\title{
ARM Microcontroller Based Wireless Industrial Automation System
}

\author{
Apar Chitransh, Birinderjit Singh Kalyan
}

\begin{abstract}
In modern era most of the work being completed by the new and advanced various technology. Most of the industries are being run on the robotics technologies. But in INDIA most of the company are running in various technologies as like embedded system, plc, Arduino for sensing the alcohol detection and gas detection system and most important thing microcontroller. In this paper we discuss the ARM microcontroller based wireless industrial automation system. This automation consists the coordinator module and sensor module. In which one module is connected with the monitoring computer that is called the coordinator module and for connecting with the monitor of the computer it is also called the centralized unit. And the sensor module is an ARM microcontroller for a monitoring and controlling the whole plant. The coordinator unit main work is to collects the all type of data from the sensor module and provide that information to the IP network. For better communication between these two modules, we use the best technology is ZIGBEE technology. Its main work to preset the changing and control the plant various parameter. ARM microcontroller using the embedded c language coding. This paper we do the deeply study about the ARM microcontroller and about the wireless industrial automation system and the term of ZIGBEE technology.
\end{abstract}

Keyword: Modules: Coordinate And Sensor, ZIGBEE Technology, ARM Microcontroller, Industrial Automation

\section{INTRODUCTION}

Microcontroller is the main important key in point of view of industrial automation and if we saw that the industrial automation is a type of collection of various parameters as like sensors, controllers, actuators. Main work of microcontroller is to connecting these parameters together and monitoring them and controlling them. To communicate with them in proper manner we need a path for an industrial automation then we use the PLC "programmable logic controller" with the help of PLC we control the sensor, timer, relay and microcontroller also. For industrial automation sensor input and controller output is made for the programing. Alarms blow on preset level. Also, in industries PLC command the such type of alternators and motors, valves etc. security and privacy are an important factor for a industrial automation. We saw in industries that most of the work of an industries are done with the wire and cable, generally the power delivered with the help of wire and this is main cause of fire ignite due to heat.

Manuscript received on 29 May 2021 | Revised Manuscript received on 05 June 2021 | Manuscript Accepted on 15 September 2021 | Manuscript published on 30 September 2021. * Correspondence Author

Apar Chitransh*, M.E. Electrical, Department of Electrical Engineering, Chandigarh University, Punjab, India.

Birinderjit Singh Kalyan, Assistant Profesor, Department of Electrical Engineering, Chandigarh University, Punjab, India.

(c) The Authors. Published by Lattice Science Publication (LSP). This is an open access article under the CC-BY-NC-ND license (http://creativecommons.org/licenses/by-nc-nd/4.0/)
That's why wireless system is necessary instead of using the wire because the wireless system is absolutely safe. In this paper we see the all type of industrial automation system with the help of arm controller.

\section{INDUSTRIAL AUTOMATION}

First, we want to know that what is automation? Then automation is that process and term which is applied to any mechanism that moves by own self. In our word we can say that industrial automation is that type of technologies which is reduced the human effort from the industry. Means in industrial automation we do the programming and controlling the all type of machine and valves with the help of microcontroller and PLC software and other type of software. For our generation it is second step of mechanization in the scope of industrialization. The main advantage of this automation is lower cost from the human effort. Basically, it eliminates the healthcare issue and paid leave of the worker. Industrial automation does not allow the any other benefit like bonus, pension and other type of medical facilities. Industrial automation divided in to two group: 1. Process plant automation 2. Manufacturing automation.

Process plant automation: In this automation most of the company depend upon the chemical process and some other raw materials. Thus, the overall process done with the automated with the help of process plant automation system with the high quality and high reliable control, more productive. The process plant automation done with some level of the process. Like level 0,1,2,3,4 and this level named is plant, direct process control level, plant supervisory control level, production scheduling \&control, plant management respectively. Level 1 consists of the machine which is close to process. Level 1 consists the automatic controller and monitoring system and want to process information from the sensors. Level 2 give the commands the automatic controller to set the target point with the time. Level 3 solve the decision-making problems like location and production target. Level 4 has a high level of the process plant automation and deals more with the commercial activities than technical activities.

Manufacturing automation: in this automation system the work is done with the help of out of machine and robotics technologies. This automation consists the machinery level, group level, shop floor level, plant level, enterprise level. In machinery level consists the all type of sensors and all type of actuator device for control. In group level operation of machines with in manufacturing cells. In shop floor level with the supervision and several on manufacturing cell.

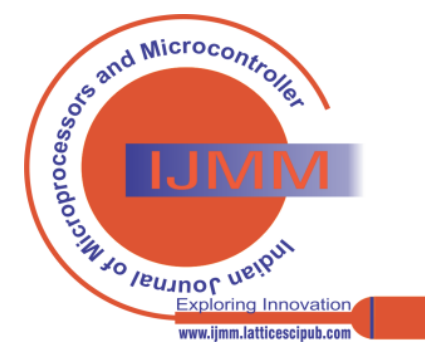


In plant level performs the all-industry activities like production, monitoring and control and time scheduling.

\section{ARM Microcontroller: -}

First of all, we know about the ARM, ARM is a processor core of a group of cortex-M which is series optimized processor for power efficiency and for determination of the operation. It widely used for microcontroller and some times it can be found in microprocessor(multi-core) and embedded system. For better instruction set and allows the more IC, they reduced the no. of transistors.

\section{ARM Architecture: -}

For reduced the instruction set it have a 32bits RISC load store architecture is present in ARM machine. In ARM, register is used instead of other equipment because the manipulation of memory is not possible directly. This instruction set offered the different variations to reduce the no. of cycle but the main focus is reducing the no of cycle. The normal execution instruction is developed by the condition of AL. for programming in ARM we see that the instruction set and decode mechanism are much simpler than the complex instruction set computers (CISC). For continuously working we use the pipeline technique. While all parts of the processing and memory system can operate continuously that time one instruction is being executed and that instruction are decoded and third instruction is being fetched from memory. For increasing the transistor from 30000 to 26 million which is support the 16bit instruction that time the thumb architecture has been developed. But it was compensated by the thumb 2. ARM architecture is consisting of two thumb technologies for different set means that for 32 bits set we use the thumb 1 and for 16-bit technologies we use the thumb 2. As usual the 32-bit processor use the 32 bits register and 16-bit processor are used the 16-bit register. Means that when all other type of microcontroller is used in one bit type of process their ARM microcontroller is use in two-bit type of processor. The 32bit processor provide the $60 \%$ of code size and 16-bit processor provide up the $160 \%$ ode size of ARM. The thumb architecture is helping to improving the compiled code density. And this is doing the sufficient work for 16-bit instructions. This architecture needs the small opcode because some opcodes cannot be accessing all registers but yes that opted the branch only. In ARM architecture DSP enhancement instruction are given for improving the ARM architect for multimedia applications and digital signal. Some time when the thumb and ARM are not available that time new technology come Infront of us which allows the execution of JAVA tie-codes in the system. Thumb 2 technology was introduced on ARM1156 and it was announced in 2003. And this is set by the 32-bit instruction. Also, the arm controller consists two analogs to digital converter. These can work at 10 bits register and doing analog to digital converter. In ADC0 has six channel and ADC 1 has 8 channel so total ARM have a 14 channel. Each converter capable of performing the 10-bit sample per sample. Measurement range of $0 \mathrm{v}$ to VREF.

\begin{tabular}{|c|c|c|c|}
\hline & 8051 & AVR & ARM \\
\hline Bus width & $\begin{array}{l}\text { 8bit for } \\
\text { standard } \\
\text { core }\end{array}$ & $8 / 32$ bit & $\begin{array}{lr}32 & \text { bits } \\
\text { mostly } & \text { and } \\
64 & \text { bit } \\
\text { available } & \end{array}$ \\
\hline $\begin{array}{l}\text { Communicatio } \\
\text { n protocols }\end{array}$ & Uart, usart & $\begin{array}{l}\text { Uart, usart } \\
\text { and special } \\
\text { purpose } \\
\text { support can } \\
\text { usb, } \\
\text { etheernet. }\end{array}$ & $\begin{array}{l}\text { Uart, usart, } \\
\text { lin,12c, spi, } \\
\text { usb, } \\
\text { ethernet, } \\
\text { 12s, }\end{array}$ \\
\hline Speed & $\begin{array}{l}12 \\
\text { clock/cycl } \\
\mathrm{e}\end{array}$ & $\begin{array}{l}1 \\
\text { clock/cycle }\end{array}$ & $\begin{array}{l}\text { 1clock/cycl } \\
\text { e }\end{array}$ \\
\hline Memory & $\begin{array}{l}\text { Rom, } \\
\text { spram, } \\
\text { flash }\end{array}$ & $\begin{array}{l}\text { Flash, } \\
\text { spram, } \\
\text { eprom }\end{array}$ & $\begin{array}{l}\text { Flash, } \\
\text { sprom, } \\
\text { eprom }\end{array}$ \\
\hline $\begin{array}{l}\text { Power } \\
\text { consumption }\end{array}$ & Average & Low & Low \\
\hline Families & $\begin{array}{l}8051 \\
\text { variants }\end{array}$ & $\begin{array}{l}\text { Tiny, } \\
\text { atmega, } \\
\text { xmega }\end{array}$ & $\begin{array}{l}\text { Armv4,5,6, } \\
7\end{array}$ \\
\hline Manufacture & $\begin{array}{l}\text { Nxp, } \\
\text { atmel, } \\
\text { silicon }\end{array}$ & Atmel, & $\begin{array}{l}\text { Apple, } \\
\text { nvidia, } \\
\text { qualcom }\end{array}$ \\
\hline Cost & Very low & Average & Low \\
\hline $\begin{array}{l}\text { Another } \\
\text { feature }\end{array}$ & Standard & $\begin{array}{l}\text { Cheap, } \\
\text { effective }\end{array}$ & $\begin{array}{l}\text { High speed } \\
\text { operation }\end{array}$ \\
\hline $\begin{array}{l}\text { Popular } \\
\text { microcontroller }\end{array}$ & At89c51 & $\begin{array}{l}\text { Atmega8,1 } \\
6\end{array}$ & $\begin{array}{l}\text { Lpc } 2148, \\
\text { arm-cortex- } \\
\text { m0 }\end{array}$ \\
\hline
\end{tabular}

Table :1 Difference between the ARM, AVR, 8051 microcontrollers

\section{Zigbee Technology: -}

Zigbee technology is a wireless technology which is opted for a low cost of an open global standard. In other word we can say that it is a low power wireless IOT network. This communication specially built for a sensor and control the industry equipment with the wireless technology on IEEE 802.15.4. this technology communication standard defines all the physical and media access control to handle many devices at low data rates. This ZigBee operate on the 867MHZ in Europe and 902MH in America and 2.3GHZ in international frequencies. Zigbee is the low cost and low powered mesh network which is control and monitoring all type of data with the range of 10 100 meter. This technology is much cheaper than the other wireless sensor and Bluetooth network. The ZigBee device can be divided into two groups 1 . Fully functional device (FFD) 2. Reduced functional device (RFD). The FFD are used in ZigBee device as like a router, for a repeater a coordinator. RFD is used as a terminal network node. FFD communicate with an RFD and FFD but RFD is directly communicating with another RFD due to it has not routing and repeat function. In structure the hardware of FFD and RFD are identical but network layer of both of them are different. The working process of ZigBee to allow the various device to converse through another.

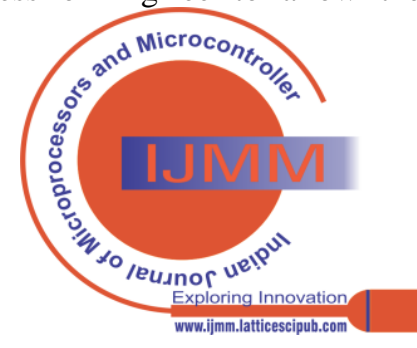


The router is used as a communicate device which main work to transfer the data or instruction from the coordinator to the single end device for an example light bulb. The coordinator system is the main device which is established at the origin of the system. The main work of router to arranged among the coordinator to the end devices which is count the message data. Router get the message from the coordinator and stored the end devices. The ZigBee technology consists the three-network topology structure: 1 . Mesh network 2. Star network 3 cluster network. In three topologies have a one or more coordinators. In star network topology, this consists the one coordinator which is responsible for the managing the device. All other device except the star network device called the end device that directly communicate with the coordinator. In mesh topologies have an extended and several routers for each device where the coordinator is responsible for staring them. In this topology structure allow the whole device to communicate with another node. The main advantage of this topology if any router fails to send the information than the information sends by next router with the next coordinator. In cluster topology consists the coordinates for each cluster with the leaf node. These coordinates connected with the parent coordinator which circulated with the entire network.
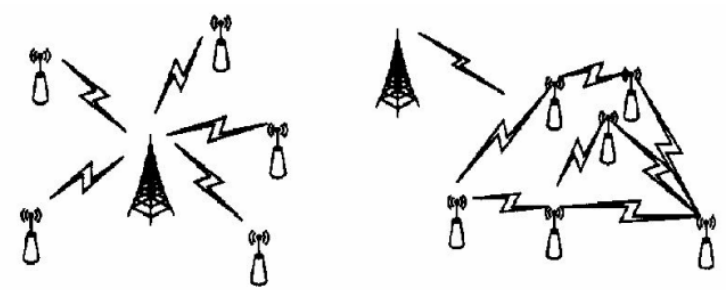

Fig:1 star and mesh network

\section{Zigbee Architecture: -}

Zigbee system consists of three type of devices 1 . Zigbee coordinator 2. Router 3. End device. As we define that every ZigBee system consists at least one coordinator which main work act as a bridge of the network. Router works as an intermediate device that permit data to pass from one end to another end. And in end device have limited function which is communicate with the parents' node. The no. of router and coordinator and end devices depend upon the topologies.

Zigbee architecture consists of some layer 1. Physical layer 2. MAC layer 3. Network layer 4. Application sub layer 5. Application frame work.

Physical layer consists of modulation and demodulation operations upon transmitting and receiving signals. MAC layer is responsible for transmit the date from taken form other source. Network layer is that type of layer which is take care of other network setup and end device connections and disconnect the router. Sublayer is enabling the processing of ZigBee device and application which is interface with the network layer of all data managing service. Application frame work has a two type of services 1. Key pair 2. Generic. In generic message service is like a developer and key pair is like attribute with the application objects.
802.15.4 architecture

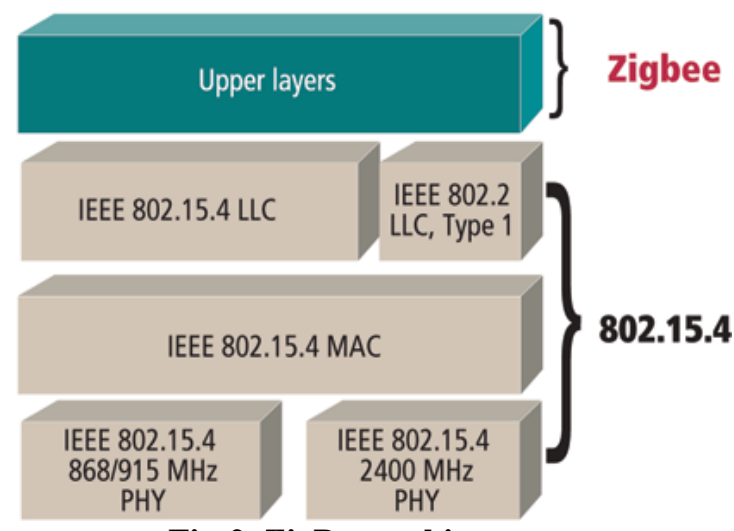

Fig:2. ZigBee architecture

\begin{tabular}{|l|l|l|}
\hline & Bluetooth & ZIGBEE \\
\hline frequency & $\begin{array}{l}2.4 \quad \mathrm{GHz}- \\
2.483 \mathrm{GHZ}\end{array}$ & $2.4 \mathrm{GHZ}$ \\
\hline channel & $79 \mathrm{RF}$ & $16 \mathrm{RF}$ \\
\hline nodes & 8 cell nodes & $\begin{array}{l}6500 \\
\text { nodes cell }\end{array}$ \\
\hline time & 3 second & 3 second \\
\hline Network range & $1-100$ meter & 70 meters \\
\hline Stack size & 250kbyte & 28kbyte \\
\hline
\end{tabular}

Table:2 Difference between the Bluetooth and ZIGBEE

\section{Wireless Industrial Automation: -}

As we discuss above the wireless technology is offer a various benefit like cost reduction, safety of product damaged by the fire and burning the cable. Most of the technology is implemented with the industrial automation system like RFID, wireless sensor network, wireless LAN, wireless WAN etc. also it improves the workspace productivity. Means when no wire is coming in to the picture than it reduced the installation and other type of effort.

Mostly the wireless industrial system consists of the coordinator of ARM where it is connected to the IP/TCP network. The coordinator module is mostly collecting the data from the sensor node and for monitoring to the system. Other side the ZigBee module main work to communicate with the coordinator module and send the data through the RS232 cable. The ZigBee module play a main role for collecting the data from the server node and sending them and receiving from the other nodes. When we put the Node controller in the system then its main work to collect the data from the server node and sending to the system on the coordinator module demand. For this reason, it does the many experiment like turn off the relay and buzzer. In sensor module the microcontroller which is we use is, was initialized and give the data also in initialized form. When the microcontroller collects the data from the any module which is we use in the form of initialized then it shows on the LCD display.

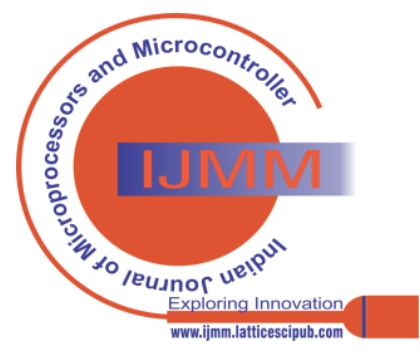




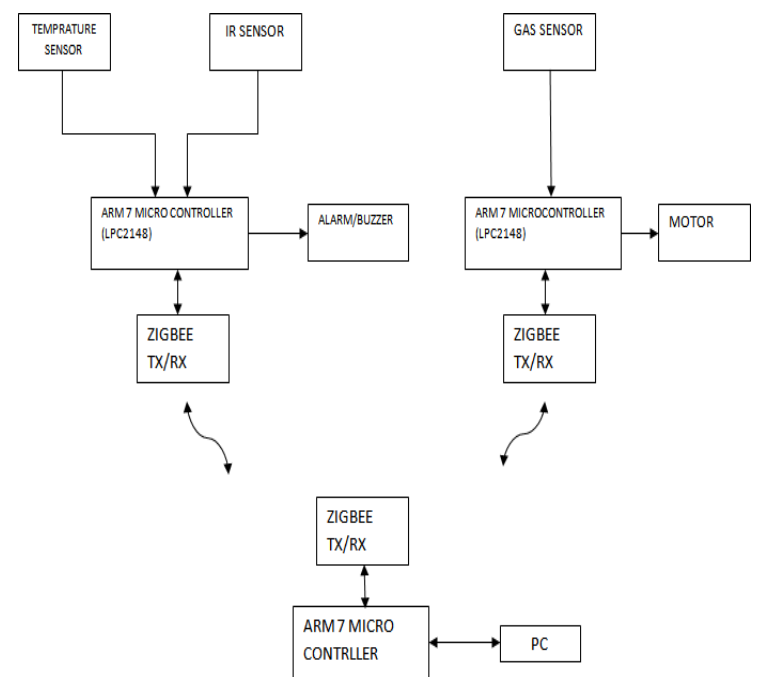

Fig: 3. wireless industrial automation architecture

\section{Flowchart: -}

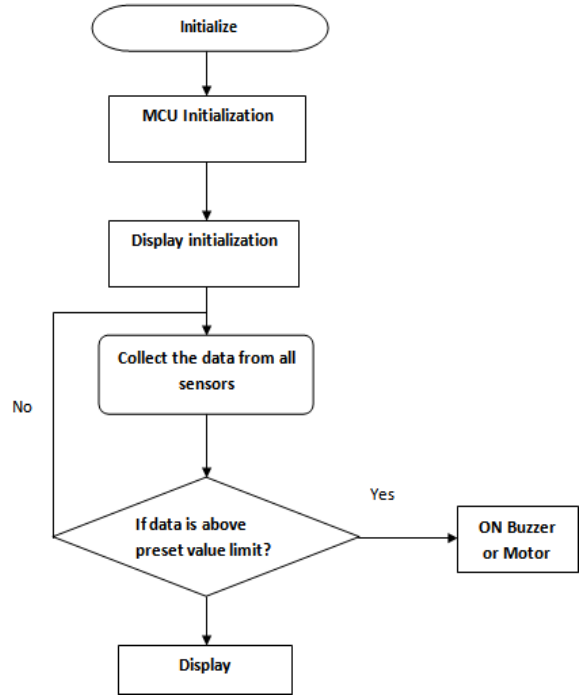

Fig: 4. process of sensor module

\section{CONCLUSION}

In this paper we see the wireless industrial automation with the help of ARM microcontroller. We discuss in detail about the ARM and their architecture and its module. In microcontroller have a two module like coordinator and sensor module which main work is to send and collect the data from Node controller with given coordinates. For doing the wireless automation we must use the Zigbee technology. And the ZigBee technology have a standard IEEE802.15. this ZigBee technology have a standard frequency which is different from country and side wise like This ZigBee operate on the 867MHZ in Europe and 902MH in America and 2.3GHZ in international frequencies. So this paper give the detail about the wireless industrial automation system, ARM microcontroller and ZigBee technology also.

\section{REFERENCES}

1. Research on ZigBee Wireless Sensors Network Based on ModBus Protocol, SciRes, Wireless Sensor Network, 2009, 1, 1-60.

2. ZigBee Alliance, ZigBee Specification [Z], http://www. ZigBee. org.

3. L. T. Cao, W. Jiang, and Z. L. Zhang, "Networked wireless meter reading system based on ZigBee technology," Control and Decision Conference, Chinese, pp. 3455-3460, 2008.

4. W. K. Park, C. S. Choi, J. Han, and I. Han, "Design and implementation of ZigBee based URC applicable to legacy home appliances," Consumer Electronics, ISCE 2007, IEEE International Symposium, pp. 1-6, 2007. [CrossRef]

5. Y. M. Zhou, X. L. Yang, X. S. Guo, M. G. Zhou, and L. R. Wang, "A design of greenhouse monitoring \& control system based on ZigBee wireless sensor network," Wireless Communications, Networking and Mobile Computing, WiCom 2007, International Conference, pp. 2563- 2567, [CrossRef]

\section{AUTHOR PROFILE}

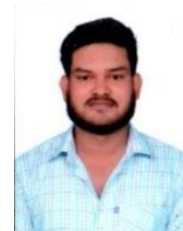

Apar chitransh, is pursuing M.E. in electrical engineering in power system specialization in Chandigarh university. His area of interest in wind energy system and power electronics devices and power system, quantum computing. He published his work without copy right in various journals and preparing for join the conferences also. till now he published more than 5 papers in international journal regarding the energy consumption and wind energy related paper. Also, member of IEEE.

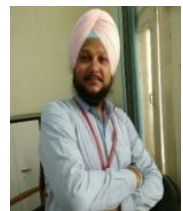

Birinderjit Singh Kalyan, Master in Microelectronics from Panjab University and Doctorate of philosophy in Quantum Computing. Published more than 50 research papers in peer-reviewed journals, reviewers of IEEE, Springer Conferences, and More than 12 Years of Experience in research and Academics.

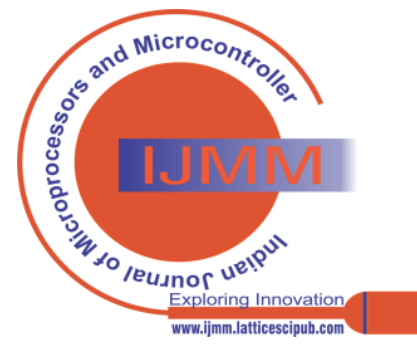

